\title{
The Development of an Educational Video on Blood Pressure Measurement for Pharmacy Students
}

\author{
Samieh Farahani $\mathbb{D}^{\prime}$ \\ Imaneh Farahani (D) \\ Bjoern B Burckhardt (iD) \\ Karin Monser ${ }^{2}$ \\ Stephanie Laeer' \\ 'Institute of Clinical Pharmacy and \\ Pharmacotherapy, Heinrich Heine \\ University Duesseldorf, Duesseldorf, \\ Germany; ${ }^{2}$ Multimedia Center, Heinrich \\ Heine University Duesseldorf, \\ Duesseldorf, Germany
}

Introduction: High blood pressure is an important worldwide health issue. Pharmacists can perform multifaceted tasks in hypertension management such as measuring blood pressure. In a time where the use of educational videos in health professions education has increased, an educational video might be an option for teaching blood pressure measurement skills to pharmacy students. This project aimed to develop an educational video tailored to pharmacy students on oscillometric blood pressure measurement in a community pharmacy setting that can be used as a self-instruction video.

Methods: The video was created with support from the university's multimedia center. The video development was roughly divided into pre-production, production, and post-production. Students' satisfaction with and perception of the video was surveyed.

Results: An 11-minute 33-second self-instruction video in the German language on proper oscillometric blood pressure measurement tailored for pharmacy students was created. Along with descriptive slides, the video delineates the necessary steps of blood pressure measurement in a community pharmacy setting in a role-play, to support students in communication with the patient. Results of a survey on the satisfaction and perception of the video from thirty-seven pharmacy students were included in the analysis and revealed that the video was well accepted by pharmacy students. Moreover, approximately $95 \%$ responded that instructional videos should be included in future pharmacy education.

Conclusion: We successfully developed an educational video on oscillometric blood pressure measurement for a community pharmacy setting. This work is a valuable form of support for faculty members, who intend to develop educational videos. This might be of interest especially during the coronavirus disease 2019 (COVID-19) pandemic, where distance learning has become highly relevant.

Keywords: pharmacy, pharmacy education, pharmacy students, educational video, selfinstruction video, blood pressure measurement

\section{Introduction}

High blood pressure is an important worldwide health issue, because of its predicted increasing prevalence ${ }^{1}$ and its attribution to dying from cardiovascular diseases, chronic kidney disease and diabetes. ${ }^{2}$ According to the global burden of disease study, high systolic blood pressure was the leading risk factor, accounting for 10.4 million deaths in 2017. ${ }^{3}$ The beneficial impact of a pharmacist's intervention alone or in collaboration with other healthcare professionals in improving blood pressure management is described in the literature. ${ }^{4}$ Pharmacists can perform multifaceted tasks in hypertension
Correspondence: Samieh Farahan Institute of Clinical Pharmacy and Pharmacotherapy, Heinrich Heine University Duesseldorf,

Universitaetsstrasse I, Duesseldorf, 40225, Germany

Email samieh.farahani@hhu.de 
management such as measuring blood pressure and educating patients on self-blood pressure measurement. ${ }^{5}$

Accurate blood pressure measurement plays a vital role for detecting hypertension and for managing patients with hypertension appropriately. Inaccurate blood pressure measurement can cause diagnostic errors and inadequate decision-making and risk assessment. ${ }^{6}$ Many sources of inaccuracy can be addressed by proper, standardized blood pressure measurement technique and validated equipment. ${ }^{7,8}$ Currently, the scientific environment and health institutions have made major efforts to optimize blood pressure measurement skills. ${ }^{6,7,9,10}$ In this context, the World Health Organization (WHO) places major emphasis on proper training of the respective personnel, even if automated blood pressure measurement devices are used. ${ }^{6}$ Consequently, this competence should be taught appropriately.

In a time where the use of educational videos in health professions education has increased, ${ }^{11,12}$ an educational video might be an option to teach this skill. Clinical teaching videos are used for several purposes, such as to deliver lectures, ${ }^{13}$ to demonstrate clinical skills, ${ }^{14}$ to show cases, ${ }^{15}$ and to provide feedback and evaluation. ${ }^{16}$ Educational videos are valuable teaching tools for health professions education $^{17-21}$ and can be used in face-to-face teaching as well as in distance teaching. ${ }^{22}$ Due to the coronavirus disease 2019 (COVID-19) pandemic, many educational institutions around the world, including universities, had to shift to distance teaching to ensure learning continuity. ${ }^{23,24}$

The ability of increasing blood pressure measurement skills by using this educational self-instruction video had been systematically investigated in pharmacy students in a randomized controlled study in which the focus of the publication was on the study design and the outcome measurement such as the objective structured clinical examination methodology. ${ }^{25}$

However, the development process of the educational video itself was only very briefly described. ${ }^{25}$ To enable the reproduction of such an instructional video by instructors of health professions faculties, the present work aims to explain the pedagogical aspects we considered and the steps we took to create an instructional video designed to teach a clinical skill using the example of oscillometric blood pressure measurement in a community pharmacy for pharmacy students. In addition, this paper presents an assessment of the video by presenting the satisfaction with and perception of the surveyed students.

\section{Materials and Methods}

The video production was divided into three main phases: pre-production, production, and post-production. ${ }^{26,27}$ The pre-production phase included all planning activities prior to the actual filming as defined in the literature, ${ }^{26,28}$ while the production phase covered all activities involving the recording of audio-visual material. ${ }^{26}$ The post-production phase consisted of the activities following the initial film recording such as editing. ${ }^{28}$ The steps applied in this project in each of the three phases are summarized in Table 1.

\section{Pre-Production}

Before starting the production of the video, we made many theoretical considerations and fundamental decisions. Among these, the purpose and target audience of the

Table I Summarized Steps of Video Production

\begin{tabular}{|c|c|c|}
\hline Pre-Production & Production & Post-Production \\
\hline $\begin{array}{l}\text { - Definition of purpose/goal of the video } \\
\text { - Identification of target audience } \\
\text { - Selection of video style } \\
\text { - Scriptwriting } \\
\text { - Decision about self-production or cooperation with profes- } \\
\text { sional production company } \\
\text { - Recruitment of actors } \\
\text { - Selection and organization of filming location, required mate- } \\
\text { - rial, and other staff } \\
\text { - Resting feasibility and clarity of script and where necessary } \\
\text { - Rehearsal of the script and scenes with the actors } \\
\text { Coordination of shooting schedule and personnel }\end{array}$ & $\begin{array}{l}\text { - Setup the filming location } \\
\text { and lighting } \\
\text { - Filming the video } \\
\text { - Recording the sound }\end{array}$ & $\begin{array}{l}\text { - Screening video footage } \\
\text { - Rough cut } \\
\text { - Re-recording sound, where necessary } \\
\text { - Sound editing } \\
\text { - Fine cut } \\
\text { - Insertion of slides, pictures, animations, and } \\
\text { transition effects } \\
\text { - Evaluation and reviewing the video, where } \\
\text { necessary revising } \\
\text { - Rendering final product into desired and } \\
\text { eligible format }\end{array}$ \\
\hline
\end{tabular}

Notes: In this table, the steps conducted for this project are summarized. The content is based on the experience of the present video project and complies with literature. ${ }^{27-30}$ Depending on the video project other steps such as taking voice-overs might be necessary. 
educational video were identified, and the video style was selected, as recommended in the literature. ${ }^{27,29}$ Our audience was pharmacy students in the eighth and final semester of their university studies.

Another step before the actual video production was the scriptwriting. ${ }^{28}$ Two pharmacists (faculty members) developed the script, based on a literature review that included, but was not limited to the standard operating procedure of the Federal Union of German Associations of Pharmacists (ABDA) as of 2017, ${ }^{31}$ the European Society of Cardiology/European Society of Hypertension (ESC/ESH) Guidelines for the management of arterial hypertension, ${ }^{32}$ and the American guideline for the prevention, detection, evaluation, and management of high blood pressure in adults. ${ }^{52}$ The script was revised in several rounds and comprised an introduction-describing the content of the film, the cast, and the locations - and two scenes. The first scene was the greeting in the community pharmacy, and the second was the actual blood pressure measurement in the community pharmacy. The script included written dialogue between the patient and the pharmacist, described further behavior and actions the actors were meant to perform, and indicated some technical instructions on shot size. Furthermore, the script already noted some elements for post-production, such as where the explanatory slides should be inserted in the video.

Another step in the pre-production phase was the recruitment of actors. ${ }^{28}$ For that purpose, we asked two pharmacy students in their final year of pharmacy studies in the scope of their scientific elective course who gave voluntary consent. One actor took on the role of a patient whose blood pressure was to be measured, and the other actor depicted the pharmacist who performed the blood pressure measurement. The feasibility and clarity of the script were tested in the scope of the rehearsals with the actors.

Moreover, the filming location, materials, and other staff were selected and organized in this phase. ${ }^{28}$ In our case, the video project was supported by the multimedia center of the university. Therefore, one internal staff member of the multimedia center and one external via the multimedia center organized professional camera operator were involved in our video project. The video was filmed in a real community pharmacy to generate an authentic community pharmacy setting. The community pharmacy was arranged by the multimedia center, and the faculty members arranged the missing requisites such as a white coat and the different cuff sizes suitable for the available blood pressure monitor (OMRON M5 Professional HEM7001-D).

\section{Production}

The video was filmed in one day by one professional camera operator with one camera in a community pharmacy in Germany. The sound was recorded via the microphone of the camera and by external microphones attached to each actor. Besides the recording, the camera operator also set up the lighting. Every scene was recorded in several pieces, with almost every piece being filmed from two perspectives: from the pharmacist's perspective, and from the patient's perspective. During the filming process, the camera operator conferred with the faculty members over the shot size and what should be in the center of the frame in order to record the blood pressure measurement appropriately. Thus, depending on the content of the respective section, some sections were filmed close-up and/or from a distance. Generally, during the production phase, the faculty members' function was to ensure that the recorded material is authentic and correct with respect to the content. ${ }^{27}$

\section{Post-Production}

In this phase, the footage was edited using the software Adobe $^{\circledR}$ Premiere ${ }^{\circledR}$ Pro CS 6 to generate an educational video. This included first assembling a rough cut. For that purpose, the video footage was screened, suitable recordings were selected, assembled, and cut. Then, the respective audio tracks recorded by the camera were allocated and selected. Moreover, chapter slides, explanatory slides with written explanations and/or pictures or other illustrations, introductory slides, and final credit slides were incorporated in the video. The chapter slides, displaying the heading of the respective segment, were intended at separating the segments and announcing the particular segment, to be demonstrated. After chapter slides, the explanatory slides were inserted where appropriate with the purpose of providing an additional written and/or pictorial summary about the steps of the blood pressure measurement to be demonstrated. The pictures demonstrated, among others, possible mistakes during the blood pressure measurement (eg, incorrect placement of the cuff), for improving understanding. Afterward, the video recording cutting and sound synchronization were refined. Moreover, transition effects were embedded, and the display duration of the slides, as well as pictures, was adjusted. 
During editing, the video as a whole was reviewed by the two faculty members and the multimedia staff member several times, and it was determined that the camera audio track was partly impaired by loud background noises. Therefore, the majority of the camera audio tracks were exchanged with audio tracks recorded by the microphones attached to the actors. Where necessary, audio tracks were re-recorded in the sound recording studio of the multimedia center. Subsequently, the synchronization of audio and video was refined again, and the sound volume was adapted. The editing task of microphone audio track allocation, as well as the compiling of slides and additional pictures, was performed by the faculty members. The illustrations, pictures, and slides were prepared in Microsoft ${ }^{\circledR}$ PowerPoint ${ }^{\circledR}$ by the faculty members. The remaining editing was performed by the multimedia staff member, whereby the process was accompanied and guided regarding content by the two faculty members to ensure the blood pressure measurement was depicted correctly. Finally, the video sequence was rendered.

\section{Personnel and Facilities}

A 6-person team was involved in creating this educational video: two faculty members (pharmacists), two pharmacy students, one staff member from the university's multimedia center, and one external via the multimedia center organized professional camera operator. The multimedia center staff member supported the project as a media expert, and the faculty members served mainly as content experts. ${ }^{27}$ Except for the ongoing personnel expenses for the two faculty members, for the faculty no additional expenditures related to the video development incurred. An oscillometric upper arm device (OMRON M5 Professional HEM-7001-D) was used in the video. Professional filming equipment was used. The video was filmed in one day in a community pharmacy in Germany during the day-to-day business to generate an authentic community pharmacy setting. The video project was approved by the ethics committee of the medical faculty of the Heinrich Heine University Duesseldorf (Study Number 2018-164_1-ProspDEuA).

\section{Online Platform}

The completed video was distributed through the university's video platform "hhu mediathek" (https://mediathek. hhu.de/), which uses a JW Player. The students attending the respective seminar were provided with a link and could access the video via student identification data.

\section{Evaluation}

To assess the students' satisfaction with and perception of the educational video, students were surveyed in the scope of an investigation on flipped classroom-like approaches. This investigation was approved by the ethics committee of the medical faculty of the Heinrich Heine University Duesseldorf (Study Number 2019-729-andere Forschung erstvotierend). The survey was distributed at the end of the seminar (in January 2020) to the students. The students were asked to rate four items concerning the usefulness of the video to convey knowledge on blood pressure measurement, to improve practical blood pressure measurement skills, the accessibility of the video via the platform, and if instructional videos should be included in future pharmacy education. A 6-point Likert scale from "strongly disagree" to "strongly agree" was used for the evaluation. Moreover, the students were required to rate the educational video, based on the German school grading scale, ranging from $1=$ very good to $6=$ inadequate. In free-text items, they had the option to give feedback regarding the particularly favored aspects of the instructional video and what they would suggest changing about the video. For analysis, the comments on the free-text items were categorized into topics.

\section{Results}

Given our aim of providing pharmacy students a guide in the form of a self-instruction tool on how to measure blood pressure with an oscillometric upper arm device appropriately in a community pharmacy setting, the video not only demonstrated the necessary steps but also delineated the blood pressure measurement process via role-play to support the students in communicating with the patient, along with descriptive slides. The video also considers factors that can potentially influence the accuracy of blood pressure measurements, implemented as pharmacist-patient interaction. The created video is also suitable for pharmacists to refresh their blood pressure measurement skills. The finalized video had a duration of 11 minutes and 33 seconds and presents oscillometric blood pressure measurement at the upper arm in a real community pharmacy setting in the German language. Table 2 describes the content and structure of the video.

\section{Evaluation}

Satisfaction and perception surveys of 37 pharmacy students were included in the analysis. As not all of these participants 
Table 2 Description of the Structure and Content of the Video

\begin{tabular}{|c|c|}
\hline Segment & Short Description of the Segment \\
\hline Introduction & - Slides showing the title of the video and information on copyright \\
\hline Greeting & $\begin{array}{l}\text { - Recording showing the patient entering the community pharmacy } \\
\text { - Recording showing the patient and pharmacist greeting and the patient asking for blood pressure } \\
\text { measurement }\end{array}$ \\
\hline Setting & $\begin{array}{l}\text { - Slides describing the required spatial and technical equipment } \\
\text { - Recording showing the spatiality for the blood pressure measurement }\end{array}$ \\
\hline $\begin{array}{l}\text { Preparation of blood pressure } \\
\text { measurement }\end{array}$ & $\begin{array}{l}\text { - Slides describing the preparation for blood pressure measurement, such as: } \\
\text { - Questions that should be asked during a patient interview } \\
\text { - How clothing is removed properly from the arm (or arms, respectively, if both arms are intended to be } \\
\text { - measured) } \\
\text { - How to choose the correct cuff size } \\
\text { - Recording showing: } \\
\text { - The pharmacist conducting the patient interview } \\
\text { - The pharmacist giving the patient instructions on how to expose arm/arms appropriately } \\
\text { - The patient exposing their arm/arms properly } \\
\text { - The pharmacist measuring the arm circumference/s of the patient properly and choosing the correct cuf } \\
\text { size accordingly }\end{array}$ \\
\hline Resting period & $\begin{array}{l}\text { - Slides describing: } \\
\text { - The duration of the resting period } \\
\text { - The instructions the pharmacist should give to the patient regarding the patient's posture and behavior } \\
\text { during the resting period } \\
\text { - Recording showing: } \\
\text { - The pharmacist informing the patient about the required resting period } \\
\text { - The pharmacist giving the patient proper instructions regarding the resting period and the patient } \\
\text { executing these instructions accordingly } \\
\text { - Slide simulating the resting period }\end{array}$ \\
\hline $\begin{array}{l}\text { Process of blood pressure } \\
\text { measurement }\end{array}$ & $\begin{array}{l}\text { - Slides and illustrations describing the process of blood pressure measurement, such as: } \\
\text { - How to put on the cuff properly } \\
\text { - The instructions the pharmacist should give to the patient regarding the patient's posture and behavior } \\
\text { for the blood pressure measurement } \\
\text { - Other important aspects of appropriate blood pressure measurement in a community pharmacy } \\
\text { - Recording showing the pharmacist measuring the patient's blood pressure accurately }\end{array}$ \\
\hline $\begin{array}{l}\text { Documentation of the blood } \\
\text { pressure measurement }\end{array}$ & $\begin{array}{l}\text { - Slides depicting the correct documentation of the blood pressure measurement } \\
\text { - Recording showing: } \\
\text { - The pharmacist documenting and informing the patient about the blood pressure } \\
\text { - The closing of the consultation }\end{array}$ \\
\hline Acknowledgments & $\begin{array}{l}\text { - Slides listing the names of the involved persons: actors, camera operator, editor, director, assistant, and } \\
\text { expression of thanks to the community pharmacy, the video was filmed at }\end{array}$ \\
\hline
\end{tabular}

filled out the survey completely, the total number of responses varied depending on the item. The results of that survey indicated that the video was highly appreciated by the students and approximately $95 \%$ of the students responded (rather agree or agree or strongly agree) that instructional videos should be included in future pharmacy education (Figure 1). Moreover,
$100 \%$ of the students indicated that the instructional video was helpful in improving their practical blood pressure measurement skills (rather agree or agree or strongly agree). The selfinstruction video was rated with a mean German school grade of $1.89(\mathrm{SD}=0.81)$ and a median of $2(\mathrm{IQR}=1)$ by the students $(n=37)$. The results of free-text items are presented in Table 3 . 
Instructional videos should be included in future pharmacy education.

$(n=37)$

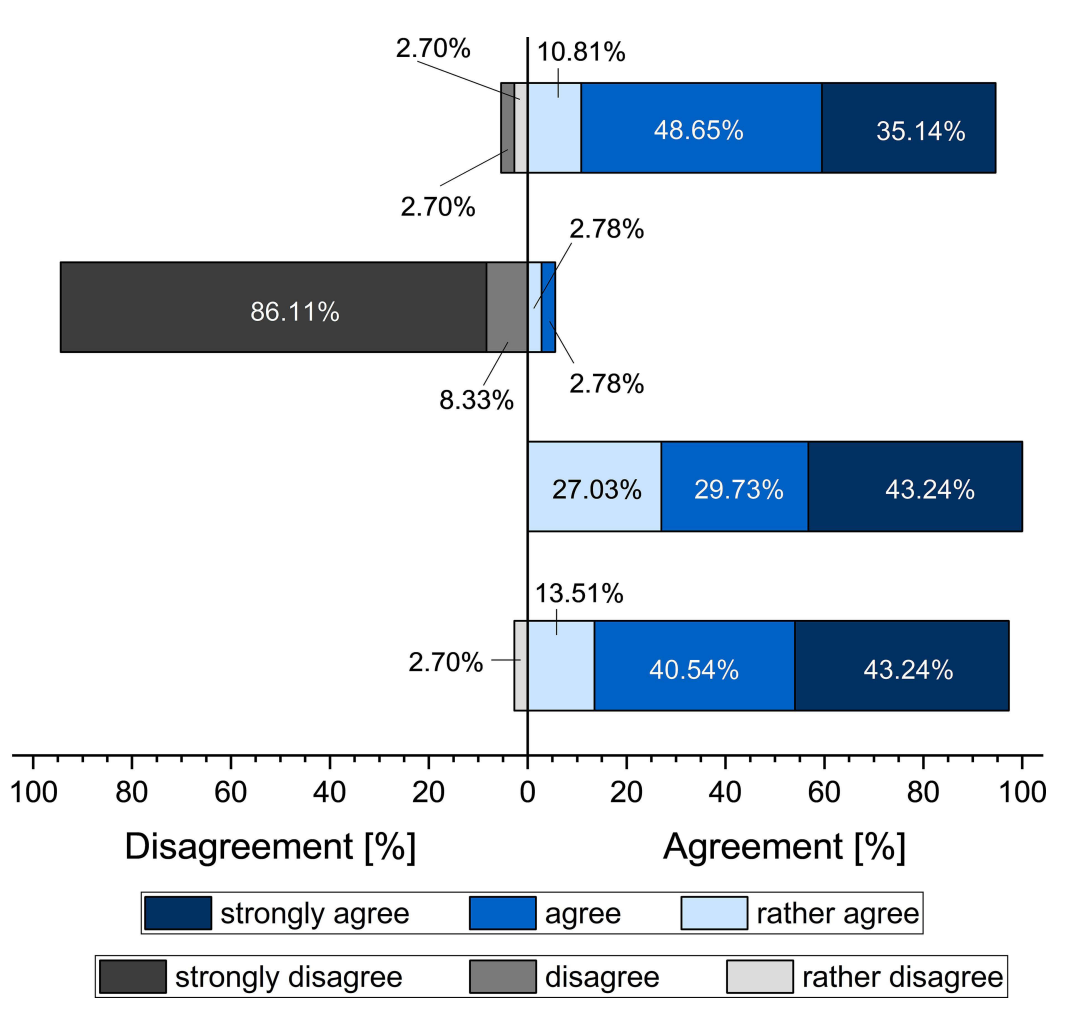

I had technical problems accessing or playing the instructional video.

$(n=36)$

The instructional video was helpful in improving my practical blood pressure measurement skills. $(n=37)$

The instructional video was helpful in conveying knowledge about measuring blood pressure. ( $n=37$ )

Figure I Students' satisfaction and perception regarding the instructional video. As not all included participants filled out the survey completely, the total number of responses varies depending on the item.

\section{Discussion}

We created an educational video in the German language on the proper oscillometric blood pressure measurement tailored for pharmacy students. The design of the video was in the form of a role-play to promote students' communication skills. The video was designed as a self-learning tool in the form of a self-instruction video. Moreover, to facilitate video production for inexperienced educators in pharmacy and medical education, we discuss some technical and pedagogical aspects we consider important for developing educational videos in the present work.

The popular video-sharing platform YouTube hosts myriad educational videos from various sources on clinical skills, including blood pressure measurement skills, ${ }^{33-35}$ with some of these videos having received millions of views. However, videos on clinical skill education available on YouTube show a highly heterogenous range of educational usefulness and/or quality. ${ }^{36-42}$ Nevertheless, peer-reviewed journals ${ }^{43}$ or health

Table 3 Example Topics of Comments on Free-Text Items of the Satisfaction and Perception Survey

\begin{tabular}{|l|l|}
\hline Free-Text Item & \multicolumn{1}{|c|}{ Topics } \\
\hline What did you particularly like about the instructional video? & $\begin{array}{l}\text { - Comprehensible and/or clear and/or detailed video (8) } \\
\text { - Combination of video and descriptive slides (6) } \\
\bullet \text { Realistic depiction (3) } \\
\text { - The actors (3) }\end{array}$ \\
\hline I would change the following on the instructional video & $\begin{array}{l}\text { - A “problem patient" should be additionally depicted (4) } \\
\text { - Shortening the video (4) } \\
\text { - The written slides should be narrated (4) } \\
\text { - The sound quality should be improved (2) }\end{array}$ \\
\hline
\end{tabular}

Notes: The four most frequent topics of comments are presented for each item, followed by the number of mentions in brackets. If topics appeared with equal frequency, one topic was chosen. 
agencies $^{9,44}$ also have published educational videos on auscultatory or oscillometric blood pressure measurement, mainly in the English language. In line with our video, for example, the video initiated by the Pan American Health Organization emphasizes factors that can potentially affect the accuracy of blood pressure measurement. ${ }^{9,44}$ These factors, such as correct cuff size, proper resting period, and proper patient posture, are of great importance for ascertaining reliable blood pressure values, ${ }^{8,45}$ which in turn can influence decision-making in the patient's antihypertensive treatment. ${ }^{6}$

When developing an educational video, the literature recommends considering cognitive load, student engagement, and active learning to maximize the utility of the video, ${ }^{46}$ which we edeavored during the development process. For example, Brame et al have suggested creating educational videos in a way giving the impression that the video is specifically for the respective students in this class to promote student engagement. ${ }^{46}$ Therefore, we recruited students of the current semester as actors, which was appreciated by the surveyed students. This effect might not be sustained, as at some point the respective future class would not recognize the acting students anymore. Nevertheless, the advantage of student actors might be the reduction of production costs, while the students themselves might benefit from this as a learning experience. An additional aspect to maintain student engagement is keeping educational videos short. However, there are different suggestions regarding the duration of an educational video. $^{12,47-49}$ Based on our survey, only a few comments on shortening our 11-minute 33-second video were stated. Therefore, we deem the length of our video as adequate.

We decided to insert chapter slides for two reasons. First, we aimed to reduce cognitive overload by segmenting the video. $^{46,50}$ Second, we sought to promote active learning by facilitating the student-controlled movement through the video by chapter slides. ${ }^{46}$ Furthermore, we made the conscious decision to add background music neither during the pharmacistpatient interaction nor to the descriptive slides to manage cognitive load. $^{50}$

Defining the target audience is of great importance, as the necessity and helpfulness of certain information may vary depending on the experience level of the audience (novice versus expert status). ${ }^{27,46}$ In our case, the target audience was pharmacy students. At our university, students attend clinical pharmacy teaching events in the seventh semester for the first time. Therefore, we aligned the content to a rather novice audience. We decided to do so in the form of a role-play, along with written and pictorial explanations, rather than a narrative demonstration, to also facilitate the impartation of communication skills.

The actual value of the developed educational video needs to be evaluated in studies on students' perceptions and the efficacy of this educational tool. Generally, the video was well accepted by the students. This complies with our study prior. ${ }^{25}$ However, the acceptance and also efficacy of educational videos might depend on the setting (for example teaching topic, incorporation of video with other teaching activities) in which the video is applied. For example, Bazyk et al compared videotaped demonstration to live demonstration in teaching a developmental evaluation to occupational therapy students and revealed that in their case students preferred live over videotaped instruction although both groups evaluated their learning experience as good. ${ }^{51}$ Nevertheless, for acquiring oscillometric blood pressure measurement skills the selfinstruction video was non-inferior to face-to-face instruction with room for improvement in students' skills. ${ }^{25}$

Some refinements regarding video development might be done in further educational videos. In terms of an educational video's interactivity, interactive and guiding questions to foster active learning might be integrated, ${ }^{46}$ where appropriate. Furthermore, we used chapter slides to positively impact active learning and to reduce cognitive overload. However, it might be more favorable if interactive features, for example, "click-forward pauses", 46 "clickable bookmarks" or "hyperlinked index"12 were used to navigate between segments. Moreover, a portion of students who watched the video in the scope of the abovementioned study suggested adding a voiceover to the descriptive slides ${ }^{25}$ which was also mentioned by some students of the present evaluation. Therefore, adding voiceover might enhance such videos further.

\section{Conclusions}

In the present work, we provided insight into pedagogical aspects and steps undertaken to create an instructional video designed to teach clinical skills using the example of oscillometric blood pressure measurement in a community pharmacy setting for pharmacy students. This work is a valuable support for faculty members who want to develop educational videos. This might be of interest especially during the COVID-19 pandemic, where distance learning has become highly relevant.

\section{Acknowledgments}

The authors thank the pharmacist Thomas Reipen for making the community pharmacy "Südapotheke" in Duesseldorf 
available as filming location. Further, the authors thank the Multimedia Center of the Heinrich Heine University for the support in the creation of the self-instruction video. The authors thank the students Armin Dabidian and Ahmad Zaki Sherzad for supporting the video as actors as well for supporting the testing of the script, and the camera operator Nicolas Schroeder for the filming.

\section{Funding}

We gratefully acknowledge that the publication fees were funded by "Universitaets-und Landesbibliothek" of Heinrich Heine University Duesseldorf. The funding organization had no role in the design, analysis and interpretation of the data; in writing the manuscript; and in the decision to publish the manuscript.

\section{Disclosure}

The authors declare that they have no known conflict of interest that could have appeared to influence the work reported in this paper.

\section{References}

1. Kearney PM, Whelton M, Reynolds K, Muntner P, Whelton PK, He J. Global burden of hypertension: analysis of worldwide data. Lancet. 2005;365(9455):217-223. doi:10.1016/S0140-6736(05)17741-1

2. Global Burden of Metabolic Risk Factors for Chronic Diseases Collaboration. Cardiovascular disease, chronic kidney disease, and diabetes mortality burden of cardiometabolic risk factors from 1980 to 2010: a comparative risk assessment. Lancet Diabetes Endocrinol. 2014;2(8):634-647. doi:10.1016/S2213-8587(14)70102-0.

3. GBD 2017 Risk Factor Collaborators. Global, regional, and national comparative risk assessment of 84 behavioural, environmental and occupational, and metabolic risks or clusters of risks for 195 countries and territories, 1990-2017: a systematic analysis for the Global Burden of Disease Study 2017. Lancet. 2018;392(10159):1923-1994. doi:10.1016/S0140-6736(18)32225-6.

4. Santschi V, Chiolero A, Colosimo AL, et al. Improving blood pressure control through pharmacist interventions: a meta-analysis of randomized controlled trials. J Am Heart Assoc. 2014;3(2):e000718. doi:10.1161/JAHA.113.000718

5. World Health Organization. Regional Office for Europe. Pharmacy-based hypertension management model: protocol and guidelines: a joint CINDI/EuroPharm forum project. Copenhagen, Denmark: WHO Regional Office for Europe; 2005. Available from: https://apps. who.int/iris/handle/10665/107638. Accessed January 23, 2021.

6. World Health Organization. WHO Technical specifications for automated non-invasive blood pressure measuring devices with cuff. Geneva, Switzerland: World Health Organization (WHO); 2020. Available from: https://www.who.int/medical_devices/publications/ tech_specs_automated_non_invasive_blood_pressure_with_cuff/en/. Accessed December 26, 2020.

7. Padwal R, Campbell NRC, Weber MA, et al. The accuracy in measurement of blood pressure (AIM-BP) collaborative: background and rationale. J Clin Hypertens (Greenwich). 2019;21(12):1780-1783. doi:10.1111/jch.13735
8. Kallioinen N, Hill A, Horswill MS, Ward HE, Watson MO. Sources of inaccuracy in the measurement of adult patients' resting blood pressure in clinical settings: a systematic review. J Hypertens. 2017;35(3):421-441. doi:10.1097/HJH.0000000000001197

9. Campbell NRC, Khalsa T, Ordunez P, et al. Brief online certification course for measuring blood pressure with an automated blood pressure device. A free new resource to support World Hypertension Day Oct 17, 2020. J Clin Hypertens (Greenwich). 2020;22 (10):1754-1756. doi:10.1111/jch.14017

10. Padwal R, Campbell NRC, Schutte AE, et al. Optimizing observer performance of clinic blood pressure measurement: a position statement from the Lancet Commission on Hypertension Group. J Hypertens. 2019;37(9):1737-1745. doi:10.1097/HJH.0000000000002112

11. Forbes H, Oprescu FI, Downer T, et al. Use of videos to support teaching and learning of clinical skills in nursing education: a review. Nurse Educ Today. 2016;42:53-56. doi:10.1016/j. nedt.2016.04.010

12. Dong C, Goh PS. Twelve tips for the effective use of videos in medical education. Med Teach. 2015;37(2):140-145. doi:10.3109/ 0142159X.2014.943709

13. Brockfeld T, Müller B, de Laffolie J. Video versus live lecture courses: a comparative evaluation of lecture types and results. Med Educ Online. 2018;23(1):1555434. doi:10.1080/10872981.2018.1555434

14. George A, Blaauw D, Green-Thompson L, et al. Comparison of video demonstrations and bedside tutorials for teaching paediatric clinical skills to large groups of medical students in resource-constrained settings. Int $J$ Educ Technol High Educ. 2019;16:34. doi:10.1186/ s41239-019-0164-Z

15. Yoon BY, Choi I, Choi S, et al. Using standardized patients versus video cases for representing clinical problems in problem-based learning. Korean J Med Educ. 2016;28(2):169-178. doi:10.3946/ kjme.2016.24

16. Pinsky LE, Wipf JE. A picture is worth a thousand words: practical use of videotape in teaching. $J$ Gen Intern Med. 2000;15 (11):805-810. doi:10.1046/j.1525-1497.2000.05129.x

17. Holland A, Smith F, McCrossan G, Adamson E, Watt S, Penny K. Online video in clinical skills education of oral medication administration for undergraduate student nurses: a mixed methods, prospective cohort study. Nurse Educ Today. 2013;33(6):663-670. doi:10.1016/j.nedt.2012.01.006

18. Mehrpour SR, Aghamirsalim M, Motamedi SMK, Ardeshir Larijani F, Sorbi R. A supplemental video teaching tool enhances splinting skills. Clin Orthop Relat Res. 2013;471(2):649-654. doi:10.1007/s11999-012-2638-3

19. Pan M, Harcharik S, Moskalenko M, Luber A, Bernardo S, Levitt J. Instructional video for teaching venepuncture[published correction appears in Clin Teach. 2014 Dec;11(7):575] Clin Teach. 2014;11 (6):436-441. doi:10.1111/tct.12198

20. Mohd Saiboon I, Jaafar MJ, Ahmad NS, et al. Emergency skills learning on video (ESLOV): a single-blinded randomized control trial of teaching common emergency skills using self-instruction video (SIV) versus traditional face-to-face (FTF) methods. Med Teach. 2014;36(3):245-250. doi:10.3109/0142159X.2013.857013

21. Lwin AT, Lwin T, Naing P, et al. Self-directed interactive video-based instruction versus instructor-led teaching for myanmar house surgeons: a randomized, noninferiority trial. J Surg Educ. 2018;75 (1):238-246. doi:10.1016/j.jsurg.2017.06.004

22. Hurtubise L, Martin B, Gilliland A, Mahan J. To play or not to play: leveraging video in medical education. $J$ Grad Med Educ. 2013;5 (1):13-18. doi:10.4300/JGME-05-01-32

23. United Nations. Policy Brief: education during COVID-19 and beyond. 2020. Available from: https://www.un.org/sites/un2.un.org/ files/sg_policy_brief_covid-19_and_education_august_2020.pdf. Accessed December 6, 2020. 
24. Marinoni G, van't Land H, Jensen T. The impact of COVID-19 on higher education around the world: IAU global survey report International Association of Universities (IAU). May 2020. Available from: https://www.iau-aiu.net/IMG/pdf/iau_covid19_and he_survey_report_final_may_2020.pdf. Accessed December 6, 2020.

25. Farahani S, Farahani I, Burckhardt BB, Schwender H, Laeer S. Selfinstruction video versus face-to-face instruction of pharmacy students' skills in blood pressure measurement. Pharmacy (Basel). 2020;8(4):217. doi:10.3390/pharmacy 8040217

26. Corbally MA. Considering video production? Lessons learned from the production of a blood pressure measurement video. Nurse Educ Pract. 2005;5(6):375-379. doi:10.1016/j.nepr.2005.04.003

27. Fleming SE, Reynolds J, Wallace B. Lights ... camera ... action! a guide for creating a DVD/video. Nurse Educ. 2009;34(3):118-121. doi:10.1097/NNE.0b013e3181a0270e

28. Elliot DL, Goldberg L, Goldberg MJ. Digital video technology and production 101: lights, camera, action. Health Promot Pract. 2014;15 (1):86-90. doi:10.1177/1524839913510722

29. Shears J. An introduction to video production. $J$ Vis Commun Med. 2006;29(2):54-60. doi:10.1080/01405110600857755

30. Kelly M, Lyng C, McGrath M, Cannon G. A multi-method study to determine the effectiveness of, and student attitudes to, online instructional videos for teaching clinical nursing skills. Nurse Educ Today. 2009;29(3):292-300. doi:10.1016/j.nedt.2008.09.004

31. ABDA - Bundesvereinigung Deutscher Apothekerverbände Geschäftsbereich Arzneimittel. Blutdruckmessung in der Apotheke: Standardarbeitsanweisung (SOP) für die Apotheke. ABDA Bundesvereinigung Deutscher Apothekerverbände Geschäftsbereich Arzneimittel. 2017. Available from: https://www.abda.de/fuer-apothe ker/qualitaetssicherung/leitlinien/leitlinien-und-arbeitshilfen/. Accessed February 17, 2019.

32. Williams B, Mancia G, Spiering W, et al. 2018 ESC/ESH Guidelines for the management of arterial hypertension [published correction appears in Eur Heart J. 2019 Feb 1;40(5):75]. Eur Heart J. 2018;39 (33):3021-3104. doi:10.1093/eurheartj/ehy339

33. Polyfit. How to: Measure Blood Pressure [Video]. YouTube; Published 2012. Available from: https://www.youtube.com/watch? $\mathrm{v}=$ Gmic13mvsgo. Accessed January 24, 2021.

34. 1mg. How to Use Digital BP Monitor (step by step) [Video]. YouTube; Published 2020. Available from: https://www.youtube. com/watch?v=BZMjLtQ2b8w. Accessed January 24, 2021.

35. Studi Couch. Körperliche Untersuchung Blutdruck Puls OSCE Studicouch [Video]. YouTube; Published 2014. Available from: https://www.youtube.com/watch?v=AUw a5q4R14. Accessed January 24, 2021.

36. Akgun T, Karabay CY, Kocabay G, et al. Learning electrocardiogram on YouTube: how useful is it? J Electrocardiol. 2014;47(1):113-117. doi:10.1016/j.jelectrocard.2013.09.004

37. Azer SA, AlGrain HA, AlKhelaif RA, AlEshaiwi SM. Evaluation of the educational value of YouTube videos about physical examination of the cardiovascular and respiratory systems. $J$ Med Internet Res. 2013;15(11):e241. doi:10.2196/jmir.2728

38. Camm CF, Sunderland N, Camm AJ. A quality assessment of cardiac auscultation material on YouTube. Clin Cardiol. 2013;36(2):77-81. doi: $10.1002 / \mathrm{clc} .22080$

Advances in Medical Education and Practice

\section{Publish your work in this journal}

Advances in Medical Education and Practice is an international, peerreviewed, open access journal that aims to present and publish research on Medical Education covering medical, dental, nursing and allied health care professional education. The journal covers undergraduate education, postgraduate training and continuing medical education
39. Azer SA, AlEshaiwi SM, AlGrain HA, AlKhelaif RA. Nervous system examination on YouTube. BMC Med Educ. 2012;12:126. doi:10.1186/1472-6920-12-126

40. Borgersen NJ, Henriksen MJV, Konge L, Sørensen TL, Thomsen ASS, Subhi Y. Direct ophthalmoscopy on YouTube: analysis of instructional YouTube videos' content and approach to visualization. Clin Ophthalmol. 2016;10:1535-1541. doi:10.2147/OPTH.S111648

41. Duncan I, Yarwood-Ross L, Haigh C. YouTube as a source of clinical skills education. Nurse Educ Today. 2013;33(12):1576-1580. doi:10.1016/j.nedt.2012.12.013

42. Şaşmaz MI, Akça AH. Reliability of trauma management videos on YouTube and their compliance with ATLS ${ }^{\circledR}$ (9th edition) guideline. Eur J Trauma Emerg Surg. 2018;44(5):753-757. doi:10.1007/ s00068-017-0803-9

43. Williams JS, Brown SM, Conlin PR. Videos in clinical medicine. Blood-pressure measurement. $N$ Engl J Med. 2009;360(5):e6. doi:10.1056/NEJMvem0800157

44. Pan American Health Organization. Virtual Course on accurate automated blood pressure measurement (2020) Virtual Campus for Public Health (VCPH/PAHO). Available from: https://www.campusvir tualsp.org/en/course/virtual-course-accurate-automated-blood-pres sure-measurement-2020. Accessed May 1, 2021.

45. Tolonen H, Koponen P, Naska A, et al. Challenges in standardization of blood pressure measurement at the population level. BMC Med Res Methodol. 2015;15:33. doi:10.1186/s12874-015-0020-3

46. Brame CJ. Effective educational videos: principles and guidelines for maximizing student learning from video content. CBE Life Sci Educ. 2016;15(4):es6. doi:10.1187/cbe.16-03-0125

47. Bordes SJ, Walker D, Modica LJ, Buckland J, Sobering AK. Towards the optimal use of video recordings to support the flipped classroom in medical school basic sciences education. Med Educ Online. 2021;26(1):1841406. doi:10.1080/10872981.2020.1841406

48. Guo PJ, Kim J, Rubin R. How video production affects student engagement. In: Proceedings of the first ACM conference on Learning@scale conference (L@S '14). Associationfor Computing Machinery; 2014:41-50. doi:10.1145/2556325.2566239

49. Lagerstrom L, Johanes P, Ponsukcharoen U. The myth of the six-minute rule: student engagement with online videos. In: Proc ASEE Annual. 2015. doi:10.18260/p.24895

50. Mayer RE, Moreno R. Nine ways to reduce cognitive load in multimedia learning. Educ Psychol. 2003;38(1):43-52. doi:10.1207/ S15326985EP3801 6

51. Bazyk S, Jeziorowski J. Videotaped versus live instruction in demonstrating evaluation skills to occupational therapy students. Am J Occup Ther. 1989;43(7):465-468. doi:10.5014/ajot.43.7.465

52. Whelton PK, Carey RM, Aronow WS, et al. 2017 ACC/AHA/AAPA/ ABC/ACPM/AGS/APhA/ASH/ASPC/NMA/PCNA Guideline for the prevention, detection, evaluation, and management of high blood pressure in adults: a report of the American College of Cardiology/ American Heart Association Task Force on Clinical Practice Guidelines. Hypertension. 2018;71(6):e13-e115. doi:10.1161/ HYP.0000000000000065 including emerging trends and innovative models linking education, research, and health care services. The manuscript management system is completely online and includes a very quick and fair peer-review system. Visit http://www.dovepress.com/testimonials.php to read real quotes from published authors. 